\title{
Desenvolvimento Luteal e Concentrações Plasmáticas de Progesterona em Vacas das Raças Gir e Nelore ${ }^{1}$
}

\section{Álan Maia Borges ${ }^{2}$, Ciro Alexandre Alves Torres ${ }^{3}$, José Reinaldo Mendes Ruas ${ }^{4}$, Vicente Ribeiro Rocha Júnior ${ }^{5}$, Giovanni Ribeiro de Carvalho ${ }^{3}$}

\begin{abstract}
RESUMO - A dinâmica folicular e a regressão luteal foram avaliadas em 12 vacas da raça Gir e em sete da raça Nelore tratadas com cloprostenol sódico entre os dias 10 e 12 do ciclo estral. A porcentagem de sincronização foi superior a $92 \%$ para as duas raças, e a ovulação do folículo dominante da segunda onda foi verificada em 72,7\% da raça Gir e em todas as vacas Nelore. O diâmetro do folículo ovulatório na raça Nelore foi inferior $(11,0 \pm 0,9 \mathrm{~mm})$ ao da raça Gir $(13,0 \pm 1,7 \mathrm{~mm})$. O intervalo médio da aplicação do luteolítico ao estro, à ovulação e o momento de ovulação após o início do estro foram de 88,7 e 91,6h, 119 e 113h, 26,5 e 24,3h para as raças Nelore e Gir, respectivamente.
\end{abstract}

Palavras-chave: bovino, cavidade luteal, corpo lúteo, zebu

\section{Follicular Dynamic and Luteal Regression in Gir and Nelore Cows after Treatment with Cloprostenol Sodic}

\begin{abstract}
The follicular dynamics and luteal regression were studied in 12 Gir and seven Nelore cows, treated with prostaglandin F2a analog, between days 10 and 12 of the estrous cycle. The synchronization rate was higher than $92 \%$ for the Gir and Nelore cows, and the ovulation of the second dominant follicle occurred in $72.7 \%$ of the Gir and all the Nelore cows. The Nelore ovulatory follicle diameter was lower than Gir cows $((11.0 \pm 0.9 \mathrm{~mm}$ x $13.0 \pm 1.7 \mathrm{~mm})$. The intervals from treatment to estrus, treatment to ovulation time and from the onset of the estrus to ovulation were 88.7 and $91.6 \mathrm{~h}, 119$ and $113 \mathrm{~h}, 26.5$ and $24.3 \mathrm{~h}$ for Nelore and Gir cows, respectively.
\end{abstract}

Key Words: bovine, corpus luteum, luteal cavity, zebu

\section{Introdução}

O corpo lúteo - uma glândula endócrina transitória que se desenvolve a partir das células da granulosa e tecais, após a ovulação do folículo dominante da última onda folicular -, tem função primária de secretar progesterona, importante na regulação do funcionamento dos órgãos genitais femininos (Smith, 1986). O desenvolvimento do corpo lúteo (CL) tem sido estudado há muitos anos por meio de palpação transretal. Com o advento da ultra-sonografia, tornou-se mais fácil e preciso o estudo das características morfológicas de CL, principalmente em animais de raças zebuínas, nas quais os CLs são considerados mais difíceis de serem detectados pela palpação, quando comparados com animais de raças européias (Galina et al., 1987).

A sazonalidade reprodutiva de fêmeas zebu tem sido relatada por muitos autores, que citam anestro e estros anovulatórios durante as estações menos favoráveis (Randel, 1984). Assim, a função luteal (Rhodes et al., 1982), a onda pré-ovulatória de LH (Harrison et al., 1982) e, conseqüentemente, a fertilidade de fêmeas Bos taurus indicus estariam alteradas no inverno em relação aos meses de verão. O conteúdo de progesterona no corpo lúteo de vacas Bos taurus indicus foi menor que em Bos taurus taurus, no verão, quando comparado com o inverno (Randel, 1984). A secreção e a concentração plasmática de progesterona apresentam variaçãocíclica durante o ciclo estral e refletem a funcionalidade do corpo lúteo entre a fase de crescimento, manutenção e regressão. Concentrações abaixo de $1 \mathrm{ng} / \mathrm{mL}$ são verificadas ao estro, elevando-se até o décimo dia, quando alcançam valores máximos de $4,5 \mathrm{ng} / \mathrm{mL}$ em vacas de raças zebuínas (Adeyemo \& Heath, 1980) e $16,0 \mathrm{ng} / \mathrm{mL}$ em vacas da raça holandesa (Badinga et al., 1994). Caso não ocorra gestação, o CL regride e as

\footnotetext{
1 Parte da tese de Doutorado do primeiro autor, parcialmente financiada pela FAPEMIG.

2 Médico Veterinário-D.S. - Rua Cap. Neves , 408. CEP:37.170-000 B. Esperança-MG. Bolsista do CNPq. E.mail: alanmborges@vet.ufmg.br

3 Professor do Departamento de Zootecnia daUFV-Av.PH Holfs, s/n o CEP:36570-000-Viçosa-MG.E.mail:ctorres@ufv.br; giovanni@ufv.br

4 Pesquisador da EPAMIG - Viçosa - MG. E.mail: jrmruas@ufv.br

5 Prof. Titular - curso de Zootecnia - Unimontes - Salinas - MG. E.mail: rochajuniorvr@hotmail.com
} 
concentrações de progesterona reduzem até valores compatíveis para a manifestação de novo estro.

A incidência e as características de corpos lúteos cavitários em vacas cíclicas tem sido mencionada em grande número de publicações, e seu desenvolvimento seqüencial pode ser acompanhado pela ultrasonografia diária, antes limitada a exames de peças de matadouro. O tempo de permanência das cavidades depende da reorganização gradual do tecido luteal e tende a desaparecer com o transcorrer do ciclo estral. A presença ou ausência de cavidade luteal não altera a concentração plasmática de progesterona de bovinos (Kito et al., 1986).

Objetivou-se com este trabalho determinar a área do corpo lúteo e das cavidades luteais, bem como o volume do tecido luteal e as concentrações de progesterona no ciclo estral de vacas das raças Gir e Nelore, em duas estações do ano.

\section{Material e Métodos}

O experimento foi conduzido em parceria da Universidade Federal de Viçosa (UFV) e a Empresa de Pesquisa Agropecuária de Minas Gerais (EPAMIG), na Fazenda Experimental de Felixlândia (MG). O período experimental compreendeu duas estações do ano: junho a agosto de 2000 (inverno) e janeiro a fevereiro de 2001 (verão).

Foram utilizadas 25 vacas da raça Gir (10 no inverno e 15 no verão) e 15 vacas da raça Nelore (7 no inverno e 8 no verão), de condição corporal boa ou muito boa, com escore 4 a 5 ( 1 = muito magra, 5 = muito gorda), de caracterização racial bem definida, não-lactantes e peso vivo médio para a raça Gir de $414 \mathrm{~kg}$ (inverno) e $416 \mathrm{~kg}$ (verão) e de $459 \mathrm{~kg}$ (inverno) e $494 \mathrm{~kg}$ (verão) para a raça Nelore. Os animais foram selecionados por meio de exame ginecológico (palpação retal e vaginoscopia) e por estarem ciclando regularmente, sendo utilizados aqueles sem qualquer alteração clínica ou reprodutiva.

As vacas foram mantidas em pastagens formadas por capim braquiária (Brachiaria decumbens $\mathrm{e}$ Brachiaria brizantha), onde recebiam mistura mineral à vontade e a água esteve disponível em bebedouros cimentados instalados nos piquetes.

A manifestação de estro foi monitorada visualmente durante uma hora, três vezes ao dia: manhã (6 às 7h), meio-dia (12 às 13h) e à tarde (18 às 19h), com o auxílio de rufião preparado por aderência peniana e equipado com buçal marcador com tinta de fácil identificação.

Os exames ultra-sonográficos foram realizados por via transretal, utilizando-se um aparelho portátil da marca ALOKA, modelo SSD-500 acoplado a um transdutor linear de 5MHz. Foram acompanhados o desenvolvimento e a regressão do maior e menor folículo presente em cada ovário, com a finalidade de monitorar o número de ondas foliculares durante o ciclo estral, verificando-se a relação entre o número de ondas com o comprimento do ciclo e a persistência do corpo lúteo. As características morfológicas do corpo lúteo foram avaliadas diariamente ao longo do ciclo estral, medindo-se a área da seção transversal $\left(\mathrm{cm}^{2}\right)$ e das cavidades luteais (área e máximo diâmetro longitudinal e transversal), segundo os procedimentos de Pierson \& Ginther (1988). A área do tecido luteal foi calculada pela diferença entre a área da seção transversal do CL e da cavidade luteal. O volume do tecido luteal e da cavidade do corpo lúteo foi calculada pela fórmula matemática: $\mathrm{V}=4 / 3 \mathrm{P} . \mathrm{a} / 2 .(\mathrm{b} / 2)^{2}$, em que $\mathrm{a}=$ eixo longitudinal $\mathrm{e}$ $\mathrm{b}=$ eixo transversal, modificada de Grygar et al. (1997). O volume da cavidade luteal foi subtraído do volume do corpo lúteo, para se determinar o volume do tecido luteal em corpos lúteos cavitários.

A temperatura ambiente foi monitorada diariamente nas duas estações do ano (inverno e verão), por meio de termômetro de máximas e mínimas e aparelho termohigrógrafo (temperatura e umidade) colocados no curral experimental. Os dados de pluviosidade foram coletados na estação meteorológica localizada na própria fazenda.

As coletas de sangue para as dosagens de progesterona tiveram início no dia do estro (dia 0) e foram realizadas a cada três dias e meio (segundafeira à tarde e sexta-feira pela manhã) até o próximo estro. As amostras foram coletadas em tubos vacuolizados de $10 \mathrm{~mL}$ contendo solução anticoagulante (EDTA), por punção da artéria ou veia coccígea, e acondicionadas em geladeira. As amostras foram imediatamente centrifugadas a 336,3 $\mathrm{g}$ durante 15 minutos para a separação do plasma, que foi transferido para tubetes plásticos previamente identificados e, então, estocado a uma temperatura de $-18^{\circ} \mathrm{C}$, até sua análise. As análises de progesterona foram realizadas no Setor de Reprodução Animal do Departamento de Zootecnia da UFV, por metodologia de radioimunoensaio (RIA), em fase sólida, utilizando-se 
"Kits" comerciais ${ }^{1}$ e seguindo-se as recomendações dos fabricantes.

$\mathrm{Na}$ análise estatística, utilizou-se o programa SAEG 8.0, aplicando-se análise de variância para as variáveis luteais, para temperatura e umidade relativa do ar. As diferenças nas concentrações de progesterona foram testadas por análise de variância e regressão, tendo como fonte de variação as estações e os dias de amostragem.

\section{Resultados e Discussão}

As duas estações do ano (inverno e verão) foram caracterizadas por diferenças $(\mathrm{P}<0,01)$ na temperatura máxima $\left(27,6\right.$ e $\left.34,3^{\circ} \mathrm{C}\right)$, temperatura mínima $\left(12,2\right.$ e $\left.21,3^{\circ} \mathrm{C}\right)$ e umidade relativa do ar $(61,0$ e $71,2 \%)$, respectivamente. A pluviosidade foi de $64 \mathrm{e}$ $97 \mathrm{~mm}$, respectivamente, no inverno e no verão, durante o período experimental.

O corpo lúteo foi detectado pela primeira vez por volta do dia 2,6 \pm 0,7 após a ovulação. Não houve variação no dia da detecção do CL, tanto para raças quanto para estação do ano. Vários relatos demonstram que os corpos lúteos podem ser detectados entre o dia 0,5 em novilhas da raça Holandesa (Kastelic et al., 1990), dia 3,3 em vacas da raça Gir (Viana et al., 1999) e dia 2 e 3 em novilhas Guzerá (Fonseca, 2000). As imagens luteais precoces aparecem com a coloração diferente do estroma ovariano, porém são de limites com características fora do padrão de corpos lúteos já formados, que é alcançado por volta do terceiro dia.

A duração do corpo lúteo não diferiu entre raças, mas foi maior em vacas apresentando três ondas foliculares (Tabela 1), quando comparado àquelas de duas ondas. A porcentagem de ciclos estrais com duas e três ondas foliculares foi de 24,0 e $68,0 \%$ para vacas da raça Gir e de 26,7 e $66,7 \%$ para as da raça Nelore, respectivamente. A duração da fase luteal é que caracteriza o número de ondas por ciclo estral (Fortune, 1994), por isso, quanto maior a persistência do corpo lúteo, maior será o número de ondas verificadas durante o ciclo estral.

Os parâmetros luteais estão relacionados na Tabela 2. Nenhum deles diferiu entre as vacas das raças Gir e Nelore, e somente a área máxima e as
Tabela 1 - Duração do corpo lúteo (dias) de vacas das raças Gir e Nelore, apresentando padrão de duas ou três ondas foliculares

Table 1 - Corpus luteum length (days) of Gir and Nelore cows showing two or three follicular waves

\begin{tabular}{lcc}
\hline Raça & \multicolumn{3}{c}{$\begin{array}{c}\text { Onda folicular } \\
\text { Follicular wave }\end{array}$} \\
\cline { 2 - 3 } & 2 ondas & 3 ondas \\
& 2 waves & 3 waves \\
\hline Gir & $15,7 \pm 0,8 \mathrm{aA}$ & $18,3 \pm 1,4 \mathrm{bA}$ \\
Nelore & $16,0 \pm 0,5 \mathrm{aA}$ & $17,9 \pm 0,9 \mathrm{bA}$ \\
\hline
\end{tabular}

Valores seguidos por letras minúsculas distintas na mesma linha, para uma mesma raça, diferem entre si $(P<0,05)$, pelo teste $F$. Valores seguidos por letras maiúsculas distintas na mesma coluna diferem entre si $(P<0,05)$, pelo teste $F$.

Values with different small letters within the row, for the same breed, differ $(P<.05)$ by $F$ test.

Values with different capital letters within column differ $(P<.05)$ by $F$ test.

taxas de crescimento e regressão do corpo lúteo foram diferentes entre as estações do ano. Por isso serão discutidos os valores médios de vacas das duas raças em conjunto.

Após a ovulação, as células foliculares do folículo rompido reorganizam-se e sofrem processos de hiperplasia e hipertrofia, culminando com a formação do corpo lúteo. À medida que as células são luteinizadas, o corpo lúteo vasculariza-se e aumenta de peso (Wiltbank et al., 1995). O acompanhamento ultra-sonográfico demonstrou que o tecido luteal foi detectado a partir de uma área de $1,1 \mathrm{~cm}^{2}$, valor igual à área do último dia em que o corpo lúteo foi detectado por ultra-sonografia (Tabela 2).

O CL aumentou de área a uma taxa de crescimento de 0,3 a $0,5 \mathrm{~cm}^{2} /$ dia, segundo ocomportamento quadrático, de forma a atingir o maior tamanho entre os dias 9,3 e 9,5 do ciclo estral (Figura 1), calculado pelo ponto de máxima. As diferenças na taxa de crescimento e regressão entre as estações (maiores no verão) podem ser explicadas pela maior área alcançada pelo CL durante os meses de verão. $\mathrm{O}$ desenvolvimento luteal implicou no aumento da área e, conseqüentemente, foi verificado também aumento proporcional no volume. Dessa forma, foi encontrada, neste experimento, elevada correlação entre a área e o volume luteal $(\mathrm{r}=0,89 ; \mathrm{P}<0,01)$. A área máxima no inverno foi de 2,9 e $3,0 \mathrm{~cm}^{2}$ e no verão, de 3,8 e $3,3 \mathrm{~cm}^{2}$, para as raças Gir e Nelore, respectiva-

${ }^{1}$ Coat-a-count Progesterone - DPC - Diagnostic Products Corporation - Los Angeles - USA. 
Tabela 2 - Parâmetros do corpo lúteo de vacas das raças Gir e Nelore, em duas estações do ano Table 2 - Corpus luteum parameters of Gir and Nelore cows, during two seasons of the year

Parâmetros do corpo lúteo Raça

Corpus luteum parameters

Breed

\begin{tabular}{cccc}
\hline \multicolumn{2}{c}{ Gir $(\mathrm{n}=25)$} & & Nelore $(\mathrm{n}=15)$ \\
\hline Inverno/2000 & Verão/2001 & Inverno/2000 & Verão/2001 \\
Winter/2000 & Summer/2001 & Winter/2000 & Summer/2001 \\
\hline
\end{tabular}

Área inicial $\left(\mathrm{cm}^{2}\right)$

Initial area $\left(\mathrm{cm}^{2}\right)$

Área final $\left(\mathrm{cm}^{2}\right)$

Final área $\left(\mathrm{cm}^{2}\right)$

Área máxima $\left(\mathrm{cm}^{2}\right)$

Maximum area $\left(\mathrm{cm}^{2}\right)$

$1,2 \pm 0,3 \mathrm{a}$

$1,2 \pm 0,1 \mathrm{a}$

$1,1 \pm 0,2 \mathrm{a}$

Dia da área máxima

$1,2 \pm 0,3 \mathrm{a}$

$1,1 \pm 0,2 \mathrm{a}$

$1,1 \pm 0,1 \mathrm{a}$

$1,0 \pm 0,1 \mathrm{a}$

Day of maximum area

Taxa de crescimento $\left(\mathrm{cm}^{2} / \mathrm{dia}\right)$

Growth rate $\left(\mathrm{cm}^{2} /\right.$ day $)$

Taxa de regressão $\left(\mathrm{cm}^{2} /\right.$ dia $)$

Regression rate $\left(\mathrm{cm}^{2} /\right.$ day)

$\begin{array}{ll}3,2 \pm 0,4 \mathrm{a}^{* *} & 4,0 \pm 0,8 \mathrm{~b}^{* *} \\ 8,9 \pm 1,4 \mathrm{a} & 9,2 \pm 1,1 \mathrm{a} \\ 0,3 \pm 0,1 \mathrm{a}^{* *} & 0,5 \pm 0,1 \mathrm{~b}^{* *} \\ 0,2 \pm 0,1 \mathrm{a} & 0,4 \pm 0,2 \mathrm{~b}\end{array}$

$3,2 \pm 0,2 \mathrm{a}^{*}$

$3,7 \pm 0,5 b^{*}$

$a, b^{* \star}$ Valores seguidos por letras minúsculas distintas na mesma linha, para uma mesma raça, diferem entre si $(P<0,01)$, pelo teste $F$. $a, b^{*}$ Valores seguidos por letras minúsculas distintas na mesma linha, para uma mesma raça, diferem entre si (P<0,05), pelo teste $F$. $a, b^{* *}$ Values with different small letters within rows, for the same breed, differ $(P<.01)$ by $F$ test.

$a, b^{*}$ Values with different small letters within rows, for the same breed, differ $(P<.05)$ by $F$ test.

$\begin{array}{ll}\text { Gir }= & \hat{Y}=0,903+0,401 D-0,020 D^{2} \\ \text { Nelore }= & R^{2}=0,95(P<0,01), \text { pelo teste " } t " \\ \hat{Y}=1,054+0,411 D-0,022 D^{2} \\ R^{2}=0,92(P<0,01), \text { pelo teste " } t \text { " }\end{array}$

Inverno/2000 (Winter/ 2000)
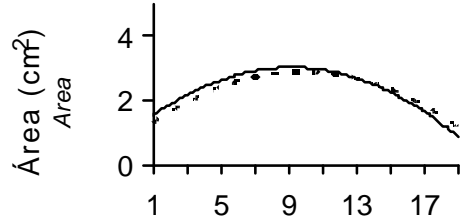

Dias do ciclo estral

Days of estrous cycle

Gir $=\quad \hat{Y}=0,431+0,573 D-0,029 D^{2}$

$R^{2}=0,92(P<0,01)$, pelo teste "t"

Nelore $=\hat{\mathrm{Y}}=0,642+0,599 \mathrm{D}-0,032 \mathrm{D}^{\circ}$

$R^{2}=0,87(P<0,01)$, pelo teste "t"

Inverno/2000 (Winter/ 2000)

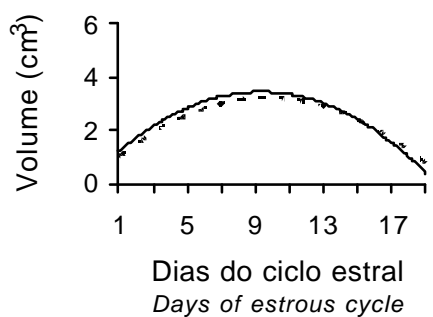

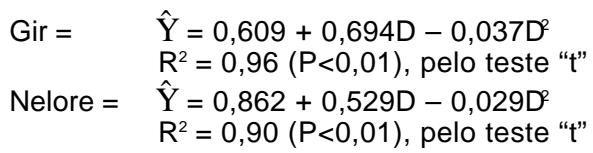

Verão/2001 (Summer/ 2001)

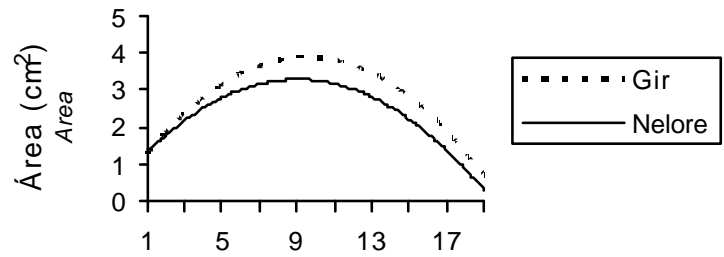

Dias do ciclo estral

Days of estrous cycle

Gir $=\quad \hat{Y}=0,060+1,085 D-0,057 D^{2}$

$\mathrm{R}^{2}=0,86(\mathrm{P}<0,01)$, pelo teste " $\mathrm{t}$ "

Nelore $=\hat{Y}=0,216+0,857 D-0,047 D^{\circ}$

$R^{2}=0,87(P<0,01)$, pelo teste " $t$ "

Verão/2001 (Summer/ 2001)

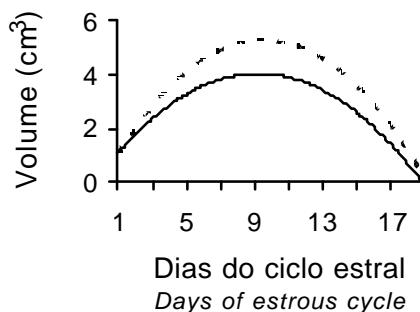

Figura 1 - Área e volume dos corpos lúteos de vacas das raças Gir e Nelore, em função dos dias do ciclo estral, para as duas estações do ano.

Figure 1 - Area and volume of the corpus luteum pf Gir and Nelore cows, according to the day of estrous cycle, during two seasons of the year.

R. Bras. Zootec., v.32, n.2, p.276-283, 2003 
mente. O volume máximo foi de 3,3 e $3,4 \mathrm{~cm}^{3}$ no inverno e de 5,2 e $3,9 \mathrm{~cm}^{3}$ no verão, para as mesmas raças. A área e o volume máximos foram calculados pelo ponto de máxima.

A área e o volume do corpo lúteo diferiram entre vacas, apresentando duas e três ondas foliculares, entre os dias do ciclo estral, e entre as raças somente no verão $(\mathrm{P}<0,01)$. As equações de regressão em função da estação do ano são apresentadas na Figura 1.

Neste experimento, não foram encontradas diferenças entre as áreas dos corpos lúteos de vacas Gir e Nelore, corroborando os valores de $3,2 \mathrm{~cm}^{2}$ encontrados em vacas da raça Gir (Viana et al., 1999). A área máxima do corpo lúteo foi verificada ao dia 9,3 e mostrou-se diferente entre as duas estações estudadas, com superioridade para os meses de verão nas duas raças (Tabela 2). Tanto a área quanto o volume foram superiores para a raça Nelore nos meses de verão. A sazonalidade reprodutiva de animais zebuínos tem sido documentada, e existem relatos de que a função do corpo lúteo e a onda pré-ovulatória de LH estão alteradas no inverno quando comparadas com os meses de verão (Rhodes et al., 1982). Estes dados indicam que influências estacionais podem ocorrer na hipófise e na função luteal dos Bos taurus indicus durante os meses mais desfavoráveis (Randel, 1984). Também, as alterações na função ovariana podem ser atribuídas à estacionalidade da produção forrageira nos sistemas de criação a pasto, que leva a alterações na condição corporal, havendo assim confundimento com o real papel da estação sobre a função reprodutiva destes animais. Os meses de verão no Brasil são caracterizados por maior pluviosidade, temperaturas mais elevadas e maior comprimento do dia, que favorecem a produção forrageira, tanto em quantidade quanto em qualidade. Forragens novas possuem melhor valor nutritivo e maior conteúdo em $\beta$-caroteno, que apresenta mecanismos de ligação nas células luteais e influencia a atividade luteal e a esteroidogênese
(Holt et al., 1995).

Entre os 40 corpos lúteos examinados por ultrasonografia (25 em vacas Gir e 15 em Nelore), 23 $(57,5 \%)$ apresentaram cavidade. Para vacas da raça Gir, a incidência de cavidade no CL foi de $64 \%$ e para a Nelore, de 46,7\%. Kito et al. (1986) encontraram cavidades em 37,2\% dos CLs de vacas da raça holandesa, enaquanto Viana et al. (1999) observaram $37,2 \%$ de cavidades nos CLs de animais da raça Gir. $\mathrm{O}$ aparecimento de cavidades luteais foi observado entre 4,8 e 6,7 dias após a ovulação. A área máxima variando de 0,1 e $0,5 \mathrm{~mm}$ foi encontrada em 78,3\% dos casos, entre o sétimo e o décimo dia (Tabela 3 ). A persistência média foi de 5,0 a 10,5 dias (Tabela 4), sendo que, em alguns casos, permaneceram por até 17 dias. A diferença no tempo de permanência das cavidades é devida à reorganização gradual do tecido luteal e tende a desaparecer com o transcorrer do ciclo estral (Kito et al., 1986). A presença das cavidades luteais em zebuínos foi verificada durante o ciclo estral (Viana et al., 1999) e na gestação (Resende et al., 1972), sendo temporária e não considerada uma condição patológica, visto que não reaparecem ao longo do ciclo estral. A taxa de gestação não é afetada pela presença de cavidades luteais, mesmo naquelas de diâmetro superior a $15 \mathrm{~mm}$, que persistem por períodos variáveis de tempo (20 dias a quatro meses) após a inseminação artificial (Kito et al., 1986). As características da cavidade não foram diferentes entre as estações do ano. Contudo, maior área e persistência foram verificadas na raça Gir, quando comparada à Nelore.

Nesse estudo não se verificou diferença $(\mathrm{P}>0,05)$ nas concentrações plasmáticas de progesterona de vacas da raça Gir com corpos lúteos cavitários ou não (Tabela 5), fato observado por Singh et al. (1997), mostrando que as cavidades luteais não interferem na fisiologia luteal (Tom et al., 1998), na duração do ciclo estral ou no estabelecimento da

Tabela 3 - Variação da área máxima da cavidade luteal e taxa de aparecimento de corpos lúteos cavitários em vacas da raça Gir e Nelore

Table 3 - Luteal cavity area maximum variation and corpus luteum appearance rate of Gir and Nelore cows

\begin{tabular}{lcc}
$\begin{array}{l}\text { Número de animais } \\
\text { Number of animals }\end{array}$ & $\begin{array}{c}\text { Variação da área máxima da cavidade }\left(\mathrm{cm}^{2}\right) \\
\text { Luteal cavity area maximum variation }\end{array}$ & $\begin{array}{c}\text { Taxa de aparecimento }(\%) \\
\text { Appearance rate }\end{array}$ \\
\hline 18 & $0,1-0,5$ & 78,3 \\
3 & $0,6-1,0$ & 13,0 \\
2 & $1,1-1,5$ & 8,7 \\
23 & & 100 \\
\hline
\end{tabular}

R. Bras. Zootec., v.32, n.2, p.276-283, 2003 
Tabela 4 - Parâmetros da cavidade luteal de vacas das raças Gir e Nelore, em duas estações do ano Table 4 - Luteal cavity parameters of Gir and Nelore cows during two seasons of the year

\begin{tabular}{|c|c|c|c|c|}
\hline \multirow[t]{3}{*}{$\begin{array}{l}\text { Parâmetros do corpo lúteo } \\
\text { Corpus luteum parameters }\end{array}$} & \multicolumn{4}{|c|}{$\begin{array}{l}\text { Raça } \\
\text { Breed }\end{array}$} \\
\hline & \multicolumn{2}{|c|}{$\operatorname{Gir}(n=25)$} & \multicolumn{2}{|c|}{ Nelore $(n=15)$} \\
\hline & $\begin{array}{l}\text { Inverno/2000 } \\
\text { Winter/2000 }\end{array}$ & $\begin{array}{c}\text { Verão/2001 } \\
\text { Summer/2001 }\end{array}$ & $\begin{array}{l}\text { Inverno/2000 } \\
\text { Winter } / 2000\end{array}$ & $\begin{array}{l}\text { Verão/2001 } \\
\text { Summer/2001 }\end{array}$ \\
\hline $\begin{array}{l}\text { Dia da detecção } \\
\text { Detection day }\end{array}$ & $5,2 \pm 3,8 \mathrm{a}$ & $4,8 \pm 1,1 \mathrm{a}$ & $6,7 \pm 0,6 a$ & $6,7 \pm 1,2 \mathrm{a}$ \\
\hline $\begin{array}{l}\text { Menor área }\left(\mathrm{cm}^{2}\right) \\
\text { Small area }\end{array}$ & $0,1 \pm 0,1 \mathrm{a}$ & $0,1 \pm 0,0 \mathrm{a}$ & $0,1 \pm 0,0 \mathrm{a}$ & $0,1 \pm 0,0 \mathrm{a}$ \\
\hline Maior área $\left(\mathrm{cm}^{2}\right)$ & $0,4 \pm 0,3 \mathrm{aA}$ & $0,6 \pm 0,3 \mathrm{aA}$ & $0,2 \pm 0,2 \mathrm{aB}$ & $0,2 \pm 0,1 \mathrm{aB}$ \\
\hline $\begin{array}{l}\text { Great area } \\
\text { Persistência (dias) } \\
\text { Persistence (days) }\end{array}$ & $8,2 \pm 5,9 \mathrm{aA}$ & $10,5 \pm 3,9 \mathrm{aA}$ & $5,3 \pm 3,1 \mathrm{aB}$ & $5,0 \pm 1,0 \mathrm{aB}$ \\
\hline
\end{tabular}

Tabela 5 - Médias e desvios-padrão das concentrações plasmáticas de progesterona em vacas da raça Gir apresentando diferentes tipos de corpos lúteos, em função do dia do ciclo estral

Table 5 - Means and standard error for plasma progesterone concentrations of Gir cows showing different kind of corpus luteum, by days of estrous cycle

\begin{tabular}{lcc}
\hline $\begin{array}{l}\text { Dia do ciclo estral } \\
\text { Days of estrous cycle }\end{array}$ & \multicolumn{2}{c}{$\begin{array}{c}\text { Progesterona } \\
\text { Progesterone }\end{array}$} \\
\cline { 2 - 3 } & $\begin{array}{c}\text { Corpo lúteo cavitário }(\mathrm{n}=23) \\
\text { Corpus luteum with cavity }\end{array}$ & $\begin{array}{c}\text { Corpo lúteo não cavitário (n=17) } \\
\text { Corpus luteum without cavity }\end{array}$ \\
\hline 0 & $0,1 \pm 0,2 \mathrm{a}$ & $0,2 \pm 0,2 \mathrm{a}$ \\
3,5 & $0,7 \pm 0,8 \mathrm{a}$ & $0,6 \pm 0,6 \mathrm{a}$ \\
7,0 & $2,8 \pm 1,5 \mathrm{a}$ & $2,3 \pm 1,4 \mathrm{a}$ \\
10,5 & $4,1 \pm 1,4 \mathrm{a}$ & $4,2 \pm 1,7 \mathrm{a}$ \\
14,0 & $5,1 \pm 1,7 \mathrm{a}$ & $5,0 \pm 1,6 \mathrm{a}$ \\
17,5 & $3,5 \pm 2,3 \mathrm{a}$ & $3,9 \pm 2,4 \mathrm{a}$ \\
21,0 & $0,2 \pm 0,2 \mathrm{a}$ & $0,2 \pm 0,2 \mathrm{a}$ \\
\hline
\end{tabular}

$P>0,05$.

gestação (Pierson \& Ginther, 1988).

As concentrações plasmáticas de progesterona dos bovinos apresentam variações durante o ciclo estral e são correlacionadas com a funcionalidade do corpo lúteo. Neste experimento, não se encontrou diferença nas concentrações de progesterona entre as raças Gir e Nelore, porém houve variação quanto à estação do ano e dias do ciclo estral $(\mathrm{P}<0,01)$ (Figura 2). Há relatos de que a resposta luteal ao LH e a produção de progesterona sofrem influência do comprimento do dia, com menores valores durante o inverno (Rhodes et al., 1982; Randel, 1984).

As diferenças observadas entre as concentrações plasmáticas de progesterona entre as duas estações do ano, com menores valores no período de verão, podem ter sido causadas pelo maior consumo de forragens de melhor qualidade. A maior disponibilidade de nutrientes aumenta o metabolismo e o fluxo sangüíneo hepático (Parr et al., 1993), levando ao maior clearance da progesterona. Também, o metabolismo da progesterona é maior em animais consumindo dietas com maior conteúdo protéico (Buttler, 1998). Como no verão existiu maior disponibilidade de forragens de melhor qualidade e de maior conteúdo protéico, menores concentrações de progesterona também foram encontradas nesta estação.

Observa-se nas curvas da Figura 2 que a concentração de progesterona é baixa no dia do estro e segue um perfil ascendente até o 14으 dia, com valores médios atingindo um máximo de $5,9 \mathrm{ng} / \mathrm{mL}$ durante o 


$$
\begin{array}{ll}
\text { Gir }= & \hat{Y}=-0,214+0,164 D-0,084 D^{2}-0,005 D^{3} \\
\text { Nelore }= & R^{2}=0,97(P<0,01) \text {, pelo teste "t" } \\
\hat{Y}=0,189-0,205 D+0,128 D^{2}-0,006 D^{3} \\
R^{2}=0,96(P<0,01), \text { pelo teste " } t \text { " }
\end{array}
$$

Inverno/2000 (Winter/ 2000)
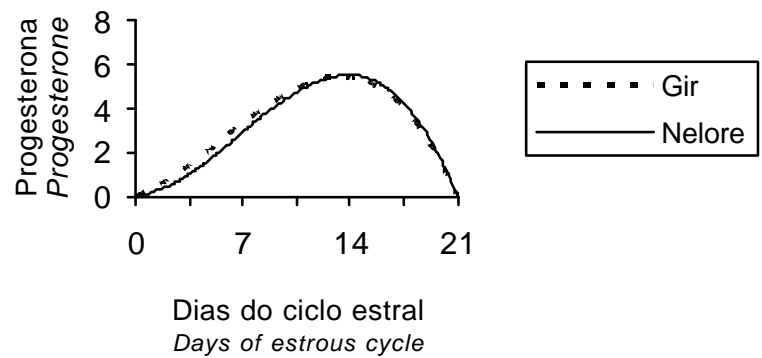

$$
\begin{array}{ll}
\text { Gir }= & \hat{Y}=0,687-0,669 D+0,165 D^{2}-0,007 D^{3} \\
& R^{2}=0,99(P<0,01), \text { pelo teste "t" } \\
\text { Nelore }= & \hat{Y}=0,063-0,107 D+0,086 D^{2}-0,004 D^{3} \\
& R^{2}=0,97(P<0,01), \text { pelo teste "t" }
\end{array}
$$

Verão/2001 (Summer/ 2001)

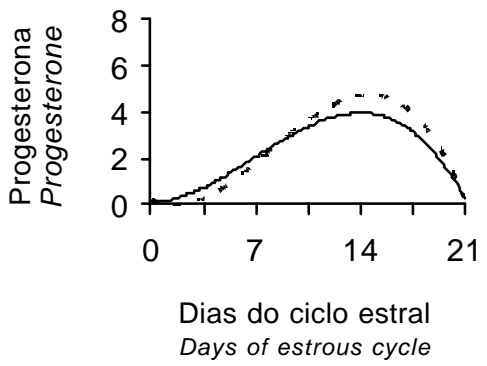

Figura 2 - Concentração plasmática de progesterona de vacas das raças Gir e Nelore em função dos dias do ciclo estral, durante duas estações do ano.

Figure 2 - Plasma progesterone concentration of Gir and Nelore cows, according to the day of corpus luteum, during two seasons of the year.

inverno/2000 e de $4,5 \mathrm{ng} / \mathrm{mL}$ no verão/2001. As maiores concentrações, para ambas as raças Gir e Nelore, variaram de 3,5 a $5,9 \mathrm{ng} / \mathrm{mL}$, entre os dias 12,1 e 14,9 do ciclo estral, calculada pelo ponto de máxima. Este aumento é devido à reorganização do tecido luteal, com posterior aumento no fluxo sangüíneo ovariano e no peso do corpo lúteo (Wiltbank et al., 1995), aumentando, conseqüentemente, a síntese de progesterona. Estes valores são semelhantes aos encontrados na literatura, tanto em animais zebuínos quanto em taurinos, de 1 a 16 ng/mL (Jiménez et al., 1988; Díaz González, 1991). Esta amplitude pode ser causada por variações inerentes aos animais, bem como pela metodologia de análise, fazendo com que a interpretação dos resultados da progesterona seja criteriosamente avaliada.

Ao se confrontarem os dados de progesterona com a área e o volume do corpo lúteo, verifica-se que as concentrações de progesterona atingem valores máximos em dias posteriores à estabilização da área e volume do corpo lúteo (nono dia). Esses resultados indicam que a maior produção de progesterona ocorre após a maturação morfológica do corpo lúteo, e não do aumento na massa do tecido luteal (Viana et al., 1999). Da mesma forma, no final do ciclo estral, o rápido declínio nas concentrações de progesterona não é acompanhado pela proporcional redução na área do corpo lúteo (Singh et al., 1997), demonstrando que a regressão funcional precede à regressão morfológica do corpo lúteo (Ribadu et al., 1994). Contudo, as correlações entre as concentrações de progesterona com a área $(\mathrm{r}=0,59 ; \mathrm{P}<0,01)$ e $\mathrm{o}$ volume $(r=0,47 ; \mathrm{P}<0,01)$ do $\mathrm{CL}$ mostraram-se médias, ao se avaliar o ciclo estral completo. Estas correlações entre a concentração de progesterona e área ou volume do corpo lúteo podem ser explicadas pelas variações na taxa de produção, secreção e clearance, que são responsáveis pelas concentrações de esteróides ovarianos (Spano \& Rosa e Silva, 1992, citados por Viana et al., 1999).

\section{Conclusões}

A presença de cavidades luteais é verificada freqüentemente durante o ciclo estral de vacas das raças Gir e Nelore e não apresentam importância patológica.

A estação do ano influenciou a área e o volume luteal, bem como as concentrações de progesterona.

\section{Literatura Citada}

ADEYEMO, O.; HEATH, E. Plasma progesterone concentration in Bos taurus and Bos indicus heifers. Theriogenology, v.14, n.6, p.411-420, 1980.

BADINGA, L.; THATCHER, W.W.; WILCOX, C.J. et al. Effect of season on follicular dynamics and plasma concentrations of estradiol-17 $\beta$, progesterone and luteinizing hormone in lactating Holstein cows. Theriogenology, v.42, p.1263-1274, 1994.

BUTTLER, W.R. Effect of protein nutrition on ovarian and uterine physiology in dairy cattle. Journal of Dairy Science, v.81, p.2533-2539, 1998.

DÍAZ GONZÁLEZ, F.H. Efeito da condição corporal de novilhas 
sobre a fertilidade, o perfil metabólico pós-serviço e a sobrevivência embrionária. Viçosa, MG: Universidade Federal de Viçosa, 1991. 118p. Tese (Doutorado em Zootecnia) Universidade Federal de Viçosa, 1991.

FERREIRA, A.M. Efeito da amamentação e do nível nutricional na atividade ovariana de vacas mestiças leiteiras. Viçosa, MG: Universidade Federal de Viçosa, MG, 1990. 134p. Tese (Doutorado em Zootecnia) - Universidade Federal de Viçosa, 1990.

FONSECA, L.M. Aspiração folicular em novilhas da raça Guzerá submetidas a tratamento hormonal com rBST associada ao FSH e dinâmica folicular durante o ciclo estral. Campos dos Goytacazes: Universidade Estadual do Norte Fluminense, 2000. 109p. Dissertação (Mestrado em Produção Animal) - Universidade Estadual do Norte Fluminense, 2000.

FORTUNE, J.E. Ovarian follicular growth and development in mammals. Biology of Reproduction, v.50, p. 225-232, 1994.

GALINA, C.S.; ORIHUELA, A.; DUCHATEAU, A. Reproductive physiology in Zebu cattle - Unique reproductive aspects that affect their performance. Veterinary Clinics of North America, v.3, n.3, p.619-632, 1987.

GRYGAR, I.; KUDLÁC, E.; DOLEZEF, R. et al. Volume of luteal tissue and concentration of serum progesterone in cows bearing homogeneous corpus luteum or corpus luteum cavity. Animal Reproduction Science, v.49, p.77-82, 1997.

HARRISON, L.M.; HANSEN, T.R.; RANDEL., R.D. Evidence for seasonal and nutritional modification of ovarian and pituitary function in crossbred heifers and Brahman cows. Journal of Animal Science, v.55, p.649-656, 1982.

HOLT, A.J.; RODWAY, R.G.; FINDLAY, J.B.C. et al. Studies on $\beta$-carotene in bovine corpus luteum. Journal of Reproduction and Fertility, v.15, p.46-47, 1995 (abstr.).

JIMÉNEZ, F.; GALINA, C.S.; DUCHATEAU, A. et al. Levels of $\mathrm{LH}$, progesterone and estradiol-17 $\beta$ during natural and $\mathrm{PGF}_{2} \alpha$ induced estrus in Indubrazil and Brown Swiss cows in the tropics. Animal Reproduction Science, v.16, p.199206, 1988.

KASTELIC, J.P.; PIERSON, R.A.; GINTHER, O.J. Ultrasonic morphology of corpora lutea and central luteal cavities during the estrus cycle and early pregnancy in heifers. Theriogenology, v.34, p.487-498, 1990.

KITO, S., OKUDA, K.; MIYAZAWA, K. et al. Study on the appearance of the cavity in the corpus luteum of the cows by using ultrasonic scanning. Theriogenology, v.25, n.2, p.325-333, 1986.

McENTEE, K. Reproductive pathology of domestic mammals. San Diego: Academic Press, 1990. 401p.
PARR, R.A.; DAVIS, I.F.; MILES, M.A. et al. Liver blood flow and metabolic clearance rate of progesterone in sheep. Research in Veterinary Science, v.55, n.5, p.311-325, 1993.

PIERSON, R.A.; GINTHER, O.J. Ultrasonic imaging of the ovaries and uterus in cattle. Theriogenology, v.29, n.1, p.21-37, 1988.

RANDEL, R.D. Seasonal effects of female reproductive functions in the bovine (Indian breeds). Theriogenology, v.21, n.1, p.170-185, 1984.

RESENDE, J.F.; MEGALE, F.; VALE FILHO, V.R. et al. Prevalência de cisto do corpo lúteo em vacas azebuadas abatidas em matadouro. Arquivos da Escola de Veterinária da Universidade Federal de Minas Gerais, v.24, p.115-117, 1972.

RHODES, R.C. III; RANDEL, R.D.; LONG, C.R. Corpus luteum function in the bovine: in vivo and in vitro evidence for both a seasonal and breedtype effect.Journal of Animal Science, v.55, p.159-167, 1982.

RIBADU, A.Y.; WARD, W.R.; DOBSON, H. Comparative evaluation of ovarian structures in cattle by palpation per rectum, ultrasonography, and plasma progesterone concentrations. Veterinary Record, v.135, p.425-457, 1994.

SMITH, M.F. Recent advances in corpus luteum physiology. Journal of Dairy Science, v.69, n.3, p.911-926, 1986.

SINGH, J.; PIERSON, R.A.; ADAMS, G.P. Ultrasound image attributes of the bovine corpus luteum: structural and functional correlates. Journal of Reproduction and Fertility, v.109, p.35-44, 1997.

TOM, J.W.; PIERSON, R.A.; ADAMS, G.P. Quantitative echotexture analysis of bovine corpora lutea. Theriogenology, v.49, p.1345-1352, 1998.

VIANA, J.H.M.; FERREIRA, A.M.; SÁ, W.F. et al. Características morfológicas e funcionais do corpo lúteo durante o ciclo estral em vacas da raça Gir. Arquivo Brasileiro de Medicina Veterinária e Zootecnia, v.51, n.3, p.251-256, 1999.

WILTBANK, M.C.; SHIAO, T.F.; BERGFELT, D.R. et al. Prostaglandin F-2a receptors in the early bovine corpus luteum. Biology of Reproduction, v.52, p.74-78, 1995. 